\title{
Os efeitos da crise financeira de 2008 no valor das empresas e nos ativos intangíveis
}

The effects of the financial crisis of 2008 in the value of companies and in intangible assets

Los efectos de la crisis financiera de 2008 sobre el valor de las empresas y activos intangibles

\section{Jonatas Dutra Sallaberry}

Mestre em Ciências Contábeis pela Universidade de Brasília

Endereço: Benjamin Constant, n 551/103, Centro

CEP: 80060-020 - Curitiba/PR - Brasil

E-mail: jonatas.sallaberry@hotmail.com

Telefone: +55 (41) 8496-6447

\section{Otávio Ribeiro de Medeiros}

Doutor em Economia pela University of Southampton, Reino Unido

Professor Titular dos programas de Pós-Graduação em Contabilidade e em Administração da Universidade de Brasília

Endereço: Campus Darcy Ribeiro - Campus Darcy Ribeiro - Prédio da FACE - Asa Norte

CEP: 70910-900 - Brasília/DF - Brasil

E-mail: otavio@unb.br

Telefone: + 55 (61) 3107-0795

Artigo recebido em 08/09/2015. Revisado por pares em 23/11/2015. Reformulado em 05/01/2016. Recomendado para publicação em 01/02/2016 por Sandra Rolim Ensslin (Editora Científica). Publicado em 30/03/2016. 


\title{
Resumo
}

A presente pesquisa tem como objetivo analisar e identificar o que ocorreu com os intangíveis e o valor de mercado na crise de 2008. A amostra foi extraída da base de dados Economática ${ }^{\circledR}$, em 40 períodos trimestrais, de 2003 a 2012. A análise identificou a relação dos intangíveis ao longo do tempo e em momentos de crise financeira, sendo que, com esta crise, foi reduzido em 74\%, uma perda superior a R $\$ 1,5$ trilhões entre 2007 e 2008 . O valor de mercado cresceu R\$ 2 trilhões, entre 2003 e 2007, enquanto o patrimônio líquido mantevese em contínuo crescimento. Assim, foi possível concluir que o mercado de capitais, no Brasil, teve uma significativa ampliação de seus intangíveis, semelhante a mercados emergentes e desenvolvidos, e na crise financeira de 2008, os intangíveis e os investidores tiveram perdas de $\mathrm{R} \$ 1,2$ e $\mathrm{R} \$ 1,5$ trilhões, respectivamente.

Palavras-chave: Crise financeira. Ativos intangíveis. Valor de mercado.

\begin{abstract}
This study aimed to analyze and identify what happened to the intangible assets and the market value in the 2008 crisis. The sample data was taken from Economática's ${ }^{\circledR}$ database referring to 40 quarterly periods from 2003 to 2012. The analysis identified the relationship of intangible assets throughout the period and during financial crisis. In the financial crisis, the intangible assets were reduced by $74 \%$ (BRL 1.5 trillion). Market value increased by BRL 2 trillion between 2003 and 2007, while equity kept a continuous growth. Thus, we conclude that the capital market in Brazil had a significant expansion of its intangible assets, similar to other emerging and developed markets, and during the 2008 financial crisis, intangible assets and market value (investors) suffered losses of BRL 1.2 and 1.5 trillion, respectively.
\end{abstract}

Keywords: Financial crisis. Intangible assets. Market value.

\section{Resumen}

Este estudio tuvo como objetivo analizar e identificar lo que pasó con los activos intangibles y el valor de mercado en la crisis de 2008. La muestra fue tomada de la base de datos Economática ${ }^{\circledR}$ en 40 períodos trimestrales desde 2003 hasta 2012. El análisis identificó la relación de intangibles en el tiempo y en tiempos de crisis financiera y la crisis financiera, se redujo en un $74 \%$, superior a BRL 1,5 billones de pérdida entre 2007 y 2008 . El valor de mercado aumentó de BRL 2 billones entre 2003 y 2007, mientras que los fondos propios se mantuvo en crecimiento continuo. Por lo tanto, se concluyó que el mercado de capitales en Brasil tuvo una expansión significativa de sus activos intangibles, como los mercados emergentes y en desarrollo, y durante la crisis financiera de 2008, lo intangible y los inversores sufrieron pérdidas de BRL 1,2 y 1,5 billones, respectivamente.

Palabras clave: Crisis financiera. Activos intangibles. Valor de mercado. 


\section{Introdução}

A função da informação financeira é fornecer uma base confiável para os que tomam decisões econômicas a respeito de organizações (HENDRIKSEN; VAN BREDA, 2011). Algumas empresas apresentam grande ampliação do valor de mercado em relação ao valor contábil do seu patrimônio que, muitas vezes, são causadas pela não contabilização de ativos intangíveis, como marcas, patentes, propaganda e publicidade, know-how, confiança dos clientes, qualidade dos produtos oferecidos, pesquisa e desenvolvimento, goodwill, capital intelectual e reputação, dentre outros.

Esses ativos intangíveis se tornaram um importante determinante da avaliação de empresas, haja vista a percepção positiva se dar pela expectativa de ganhos superiores, pelos quais os investidores estão dispostos a oferecer um prêmio superior ao valor contábil (CHOI; KWON; LOBO, 2000), agregando valor às empresas. Essa ampliação do valor de mercado tem ocorrido de forma bastante acentuada (LEV, 2001).

Segundo Boulton, Libert e Samek (2001), as organizações estão criando valor de uma maneira nova, utilizando combinações de ativos tangíveis e intangíveis, sendo que alguns ainda não são reconhecidos adequadamente. $\mathrm{O}$ fato de que os mercados agregam preferências individuais, transforma-os em indicadores potenciais da demanda de informação pela sociedade, o que tem induzido muitas pesquisas sobre o funcionamento de tais mercados (BARTH; BEAVER; LANDSMAN, 2001).

Barth, Kasznik e McNichols (2000) destacam que os intangíveis representam um aspecto importante no mundo empresarial globalizado, sejam reconhecidos ou não. A valoração dos intangíveis derivados das preferências do mercado pode ser testada em momentos de maior oscilação dos valores, como em tempos de crise ou euforia.

A proposta de pesquisa surgiu com o intuito de analisar e identificar o que ocorreu com os intangíveis e o valor de mercado na crise de 2008. Além de incorporar os intangíveis, o trabalho pretende demonstrar os efeitos que uma crise financeira pode causar no intangível não reconhecido. Para operacionalização da pesquisa, considera-se o valor de mercado derivado do preço e da quantidade de ações enquanto os intangíveis são considerados pelos seus valores contábeis e pela diferença entre o valor de mercado e o valor contábil.

A principal contribuição pretendida por este estudo é identificar o que ocorreu com os intangíveis e o valor de mercado das empresas brasileiras na crise financeira de 2008, bem como fornecer evidências empíricas da relação entre os intangíveis e o valor de mercado das empresas, tendo como diferencial a inclusão dos intangíveis já reconhecidos, haja vista outros estudos anteriores partirem do pressuposto de que os intangíveis seriam a diferença entre valor contábil e valor de mercado. A importância de conhecer esse ambiente, para os contadores, revela-se por proporcionar subsídios para mensuração dos ativos evidenciados nas demonstrações contábeis (HENDRIKSEN; VAN BREDA, 2011).

\section{Referencial Teórico}

O mercado é o ambiente onde as empresas poderiam tomar suas decisões de produção e investimento, enquanto os investidores estariam livres para aplicar seus recursos nas ações das empresas de interesse (FAMA, 1970). A teoria da Hipótese de Mercado Eficiente (HME) foi desenvolvida por Fama $(1970,1991)$ considerando que as informações relevantes das 
empresas negociadas no mercado são incorporadas aos preços dos ativos, e que a melhor estimativa para o preço de um título é seu preço atual. Assim, a diferença entre a posição inicial e a final representaria os ganhos ou as perdas do investidor, decorrentes da maior ou menor avaliação dos seus ativos pelo mercado.

Essa teoria dominou por cerca de 40 anos os estudos nos mercados de ações, preconizando que os investidores são racionais, e o mercado é eficiente na precificação dos ativos financeiros. Por isso, um desvio qualquer nos valores fundamentais poderia ocorrer, mas seria rapidamente corrigido por meio da arbitragem (FERNANDES, 2008). Sob um mercado eficiente, os preços dos títulos refletiriam plenamente toda a informação disponível, de modo que seria impossível obter lucros econômicos negociando com base nessas informações (FAMA, 1970; WATTS; ZIMMERMAN, 1986).

As condições suficientes para obtenção de um mercado eficiente, segundo Fama (1970), decorrem da existência de informações disponibilizadas sem custos e de forma igualitária para todos os participantes, da ausência de custos de transação nas negociações e das expectativas homogêneas dos investidores sobre o efeito das informações divulgadas em relação aos preços atuais e fluxos de caixa futuros.

Para que o mercado fosse eficiente, seria necessário que toda a informação útil e disponível se incorporasse aos preços dos títulos imediatamente de forma não enviesada (HENDRIKSEN; VAN BREDA, 2011).

Os preços das empresas negociadas correspondem às expectativas econômicas sobre as entidades que patrimonialmente são compostas de bens, direitos e obrigações, entre os quais os intangíveis. Os ativos intangíveis são ativos sem substância física empregados na geração de benefícios produtivos (HITCHNER, 2006; HENDRIKSEN; VAN BREDA, 2011). Lev (2001) define um ativo intangível como um direito de benefícios futuros que não tem uma personificação física ou finnanceira. Flower (2002) requer ainda que sejam identificados se os benefícios são prováveis e se seu custo ou valor pode ser mensurado com confiabilidade.

Martins (1972) comenta que há dificuldade em defini-lo, procurando demonstrar que um bem intangível dificilmente continua com característica de ativo caso seja separado do seu contexto. Hendriksen e Van Breda (2011) exemplificam citando os seguintes intangíveis: nomes de produtos, direitos autorais, franquias, goodwill, licenças, patentes, marcas, entre outros. Todas essas rubricas citadas, de fato, poderiam ser contabilizadas em contas específicas do intangível, mas nem sempre é possível identificá-las independente das demais.

As empresas que vendem produtos ou serviços são avaliadas geralmente pelos investidores com base nos lucros. Pelo menos em tese, as empresas que mantêm uma taxa de retorno superior ao 'retorno justo' do ativo líquido obtêm valores de mercado superiores ao valor contábil - o que implica que a empresa tem elementos de valor intangível que provavelmente não estão reconhecidos ou estão subavaliados (HITCHNER, 2006).

O reconhecimento de um item como ativo intangível exige que a entidade demonstre que ele atende: (a) à definição de ativo intangível; (b) aos critérios de reconhecimento, como a provável fruição dos benefícios econômicos futuros gerados em favor da entidade; e, (c) a que o custo do ativo possa ser mensurado com confiabilidade (IAS 38, n. 18-21, 2011). Hendriksen e Van Breda (2011, p. 388), baseados no parágrafo 63, da SFAC 5, orientam que um ativo intangível deve ser reconhecido, somente "[...] quando (a) corresponde à definição apropriada; (b) é mensurável; (c) é relevante; e (d) é preciso".

Esses ativos devem também representar benefícios econômicos futuros prováveis, obtidos ou controlados pela entidade como resultado de transações ou eventos passados. $\mathrm{O}$ 
Comitê de Pronunciamentos Contábeis (CPC) definiu que o ativo intangível é um ativo não monetário identificável sem substância física (CPC 04, 2010). Segundo Scott (2007), ativos intangíveis são importantes ativos para muitas empresas e, para algumas, compreendem a maior parte do valor da empresa.

Hitchner (2006) explica que a identificação dos ativos intangíveis é tão ampla quanto a mente é criativa. Os intangíveis desenvolvidos internamente precisam passar por um teste de reconhecimento antes que possam ser registrados nas demonstrações contábeis da empresa como no caso de uma combinação de negócio no qual o adquirente identifica a vantagem, mensura e reconhece como contrapartida do pagamento, validando a estimativa de tais intangíveis.

Segundo Hendriksen e Van Breda (2011), os ativos intangíveis podem ser identificáveis ou não identificáveis. Os ativos tornam-se identificáveis à medida que são associados a uma descrição objetiva. Quanto aos não identificáveis, como afirma a denominação, não é possível definir com clareza sua origem. O mais conhecido entre os não identificáveis é o goodwill. Supondo a identificação e mensuração objetiva de cada elemento dos intangíveis, o goodwill continuaria existindo segundo o conceito de goodwill sinergístico (ANTUNES; MARTINS, 2002).

O goodwill é o excesso do custo de aquisição de uma entidade sobre seus ativos e passivos assumidos, sob o fundamento da expectativa de rentabilidade futura, e decorre da redução dos lucros futuros esperados que não costuma ser registrado em virtude dos problemas de falta de objetividade (HICTHNER, 2006; IUDICIBUS, 2010).

Catlett e Olson (1968 apud SANTOS et al., 2007) definem o ativo goodwill como um benefício ou vantagem na maneira como se comporta um negócio adquirido, além do valor pelo qual ele seria vendido, devido à personalidade daquele que o conduz, à natureza da sua localização, à sua reputação habilidosa ou precisa, ou a qualquer outra circunstância incidental para o negócio que tenda a fazê-lo duradouro.

Outra forma de classificação relaciona-se à origem: objetivo ou subjetivo. O goodwill objetivo é aquele adquirido na compra de um negócio de terceiros, enquanto o goodwill subjetivo revela-se quando o ativo é criado internamente na empresa. Embora os intangíveis não sejam possíveis de serem vistos, tocados, pesados ou medidos, tais itens devem contar com proxies ou medidas indiretas (HITCHNER, 2006).

Iudícibus (2010) e Hendriksen e Van Breda (2011) apontam três perspectivas de análise do goodwill: (a) como o excesso de preço pago pela compra de um empreendimento sobre o valor de mercado de seus ativos líquidos; (b) como o excesso de valor pago pela companhia-mãe por sua participação sobre os ativos líquidos da subsidiária; e (c) como o valor atual dos lucros futuros esperados, descontados o que se esperaria sem o goodwill.

Nos dois primeiros casos, referindo-se ao goodwill objetivo, o goodwill assume-se como o excesso do custo de uma entidade adquirida sobre conjunto de ativos adquiridos menos passivos assumidos (HITCHNER, 2006).

O terceiro caso, tipicamente de goodwill subjetivo, decorrente de expectativa de lucros futuros a serem gerados pela própria empresa, é mensurado pelo valor presente de lucros superiores. Para isso seria necessário identificar o retorno normal de mercado para o negócio, e reduzi-lo dos lucros futuros esperados.

No contexto da expectativa de rentabilidade futura, acabam sendo misturados diversos tipos de ativos intangíveis como o capital intelectual, outros intangíveis identificáveis, como marcas e patentes, e não identificáveis, como know-how. 
Seguindo as normas, valiosos ativos intangíveis, como capital intelectual, marcas, pesquisa e desenvolvimento, muitas vezes não são inseridos no balanço devido a não ocorrência do evento de validação do reconhecimento o que suscita críticas de que os relatórios financeiros atuais não são confiáveis ou úteis (BALLOW; BURGMAN; MOLNAR, 2001; LEV, 2001; GHOSH; WU, 2007). Outros resultados empíricos, baseados em análises de carteira, indicam que o mercado financeiro percebe positivamente os ativos intangíveis evidenciados no balanço, mas é insensível às despesas de amortização (CHOI; KWON; LOBO, 2000).

Os ativos intangíveis são potenciais maximizadores do resultado global e da rentabilidade, motivo pelo qual os investidores precificam esses benefícios futuros adquirindo ações por um valor maior do que seu correspondente patrimônio líquido contábil. Assim, o valor de mercado de uma empresa já considera a capacidade dos ativos intangíveis da empresa de gerar valor (CHAN; LAKONISHOK; SOUGIANNIS, 2001; BELEM; MARQUES, 2012).

Nas últimas décadas a relação entre o valor de mercado e o valor contábil (market-tobook ratio) tem tido uma grande ampliação (LEV, 2001).

Salamudin et al. (2010) identificaram o desenvolvimento de intangíveis entre 2000 e 2006 e compararam a relação dos ativos intangíveis com o valor de mercado. Lev (2001, $2003,2004,2005)$ é um dos principais autores que estudou os intangíveis no mercado financeiro. Perez e Fama (2006) também analisaram a intangibilidade das companhias americanas constatando que as empresas com maior intensidade de intangíveis apresentam desempenho econômico superior.

Para os intangíveis identificáveis, Barth et al. (1998) apuraram resultados em sua pesquisa que sugerem que as estimativas são relevantes e suficientemente confiáveis para ser refletida nos preços das ações. No Brasil, Machado e Famá (2011) analisaram os dados das 120 maiores empresas brasileiras listadas na BM\&FBOVESPA, de 2002 a 2007. Os autores identificaram que o cluster com as empresas do segmento do Novo Mercado, com maiores práticas de governança, possui maior média de intangibilidade.

Embora o foco da norma local, relacionada ao reconhecimento de intangíveis, referirse ao goodwill adquirido, patentes e franquias, é possível ampliar o sentido de intangível para a diferença entre valor de mercado da empresa e valor contábil do patrimônio, semelhante à modelagem de mensuração empregada para outros termos usados por pesquisadores, como reserva oculta (KANE; UNAL, 1990); capital intelectual (ROSS; ROSS, 1997); valor oculto (EDVINSON; MALONE, 1997); reputação (ROBERTS; DOWLING, 2002); e valor inexplicável (LEV, 2004).

Salamudin et al. (2010) também identificaram o desenvolvimento de intangíveis entre 2000 e 2006, o que demanda a necessidade de realizar a análise gráfica e estatística dos dados para identificar o que vem acontecendo com o patrimônio das empresas brasileiras na última década. Essa parcela dos ditos intangíveis não reconhecidos são afetados significativamente pela percepção dos investidores que, por sua vez, são sensíveis às crises financeiras. O efeito no valor de mercado, derivado de crises financeiras, motiva a busca por evidências empíricas sobre a forma como se comportam os intangíveis das organizações em momentos de crises financeiras.

Em virtude disso, instituiu-se a hipótese de que os ativos intangíveis reconhecidos e não reconhecidos têm aumentado ao longo do tempo, da mesma forma que, em momentos de crise financeira, os ativos intangíveis são corroídos, tanto os reconhecidos, quanto os não 
reconhecidos. Assim, formula-se a hipótese de pesquisa.

Hipótese de pesquisa: $\mathrm{O}$ valor dos ativos intangíveis são corroídos em momentos de crise financeira.

A presente análise utiliza principalmente dados de acesso externo, no entanto não deixa de abordar os valores contábeis analíticos das contas, o que justifica a ênfase em autores da área de Contabilidade Financeira sem dispensar os conceitos de Contabilidade Gerencial. A Contabilidade Gerencial e a Contabilidade Financeira têm usuários diferentes (internos e externos), mas ambos os ramos da Contabilidade tendem a ser fonte básica do processo decisório para usuários internos que têm acesso a informações de maior profundidade, e para os externos que teriam maior assimetria de acesso a tais informações (FREZATTI; AGUIAR; GUERREIRO, 2007).

\section{Metodologia da Pesquisa}

Nesta etapa, o pesquisador promove o processo de estudo, construção, investigação e busca, que relaciona e confronta informações, fatos, dados e evidências, visando à solução de um problema sobre a realidade social (MARTINS; THEÓPHILO, 2009).

No ambiente contábil, pode-se observar, identificar, definir e solucionar problemas práticos do negócio. Isso tudo requer a especificação da questão de pesquisa, o desenvolvimento de hipóteses e estratégias alternativas de implementação (SMITH, 2003). A presente pesquisa tem natureza aplicada na área da ciência contábil por meio de estudo exploratório-descritivo da oscilação dos valores de mercado das empresas e de grupos de contas contábeis.

Nesse contexto, as pesquisas positivistas procuram prever comportamentos de determinada população, ou fenômeno, usualmente apoiado no método indutivo, estabelecendo as hipóteses que devem ser testadas antes de chegar a conclusões parciais (IUDÍCIBUS, 2010). Assim, identificar o comportamento dos valores dos intangíveis e das empresas permite criar conhecimento sobre fatos semelhantes.

A abordagem de mercado é um dos vários métodos empregados na avaliação de empresas, sendo que o analista precisa decidir quanto à importância do valor derivado da abordagem do mercado na avaliação global (HITCHNER, 2006). No intuito de verificar o que ocorre com os intangíveis e o valor de mercado, em sentido amplo, o estudo utilizou todos os segmentos empresariais, sem excluir as entidades do sistema financeiro nacional a fim de poder evidenciar a completude do mercado brasileiro. Inicialmente foram coletados dados de todas as empresas do Brasil e, por meio de uma planilha eletrônica, foram empilhados desde o trimestre mais antigo até o mais recente.

Para o desenvolvimento da hipótese de pesquisa, foi proposta a análise gráfica, dispensando o desenvolvimento de um modelo econométrico. Mesmo assim, alguns procedimentos técnicos e estatísticos precisaram ser empregados para se chegar à análise.

Inicialmente foram selecionadas todas as empresas brasileiras que apresentaram dados na base de dados Economática ${ }^{\circledR}$, em 61 períodos trimestrais, tendo início no quarto trimestre de 1997 até o quarto trimestre de 2012. Num segundo momento, foram excluídas as empresas que não apresentaram dados em todos os períodos, sendo limitada a amostra, em ordem decrescente, até o primeiro trimestre de 2003. Assim, a amostra foi reduzida de 572 para 147 empresas. 
Conforme ressalta Fernandes (2008), existe a necessidade de se corrigirem os dados pela inflação do período. Com base no total de empresas, com dados disponíveis de 2003 a 2012, foram gerados gráficos das informações financeiras corrigidas pelo IPCA. Para identificação da relação entre o valor de mercado e do intangível não reconhecido, os dados foram corrigidos pelo IPCA e plotados em gráfico, empregando as seguintes variáveis: valor de mercado, patrimônio líquido e intangível não reconhecido, que se dá pela diferença entre as variáveis citadas anteriormente. A partir do valor total agrupado, foi extraída a média das valores das empresas, e comparada a variação entre um período e o seguinte.

$$
\text { TaxadeCrescimento }{ }_{t}=\left(\frac{M_{t}-M_{t-1}}{M_{t-1}}\right)
$$

As taxas de crescimento individualizadas variaram no tempo, oscilando entre taxas negativas e positivas. A partir de então, foi estabelecida a taxa de crescimento de cada empresa em dado momento. Agrupadas por período, foram plotadas a média e a mediana de cada intervalo para análise.

Em relação aos ativos reconhecidos, cujos dados têm cortes temporais devido a alterações na legislação societária com a criação e extinção de grupos de contas, optou-se por apresentá-las plotadas em gráficos pelo montante de todas as empresas que apresentaram observações. Segundo Kerr e Darroch (2004), tudo que a empresa cria e é percebido pelos possíveis investidores, de alguma forma integra o valor de mercado da empresa. Como os intangíveis são potenciais maximizadores do resultado e da rentabilidade, aqueles intangíveis, reconhecidamente geradores de resultados posteriores, poderiam ser melhores sinalizadores ao mercado, vindo a resultar numa avaliação superior das ações.

Inspirado em Perez e Fama (2006) que identificaram que as empresas que geram maior valor aos seus acionistas são aquelas com maior quantidade de intangíveis, considerados os não reconhecidos, evidenciados pelo seu grau de intangibilidade, optou-se por considerar tal proxy empiricamente como determinante dos intangíveis não reconhecidos. Assim, a diferença entre o valor de mercado e o valor contábil refletiria o agregado de intangíveis não reconhecidos (BARTH; KASZNIK; MCNICHOLS, 2000). Por meio desse indicador, pode-se identificar, de forma relativa, o quanto o mercado percebe as expectativas de retorno da empresa em relação ao patrimônio demonstrado na Contabilidade, evidenciada a intensidade da avaliação do mercado em relação àquela demonstrada no patrimônio líquido da entidade (BEAVER; RYAN, 1993).

\section{Resultados e Análise}

A pesquisa buscou verificar os ativos intangíveis reconhecidos e não reconhecidos ao longo do tempo e seu comportamento em momentos de crise financeira, se de fato tais intangíveis são corroídos. Para isso, inicialmente foram gerados gráficos das informações financeiras corrigidas pelo IPCA, que são demonstradas no Gráfico 1.

O gráfico geral evidencia a oscilação das variáveis valor de mercado, patrimônio líquido, intangível, goodwill, diferido, ágio e o intangível não reconhecido, durante sua trajetória de 2003 a 2012. 


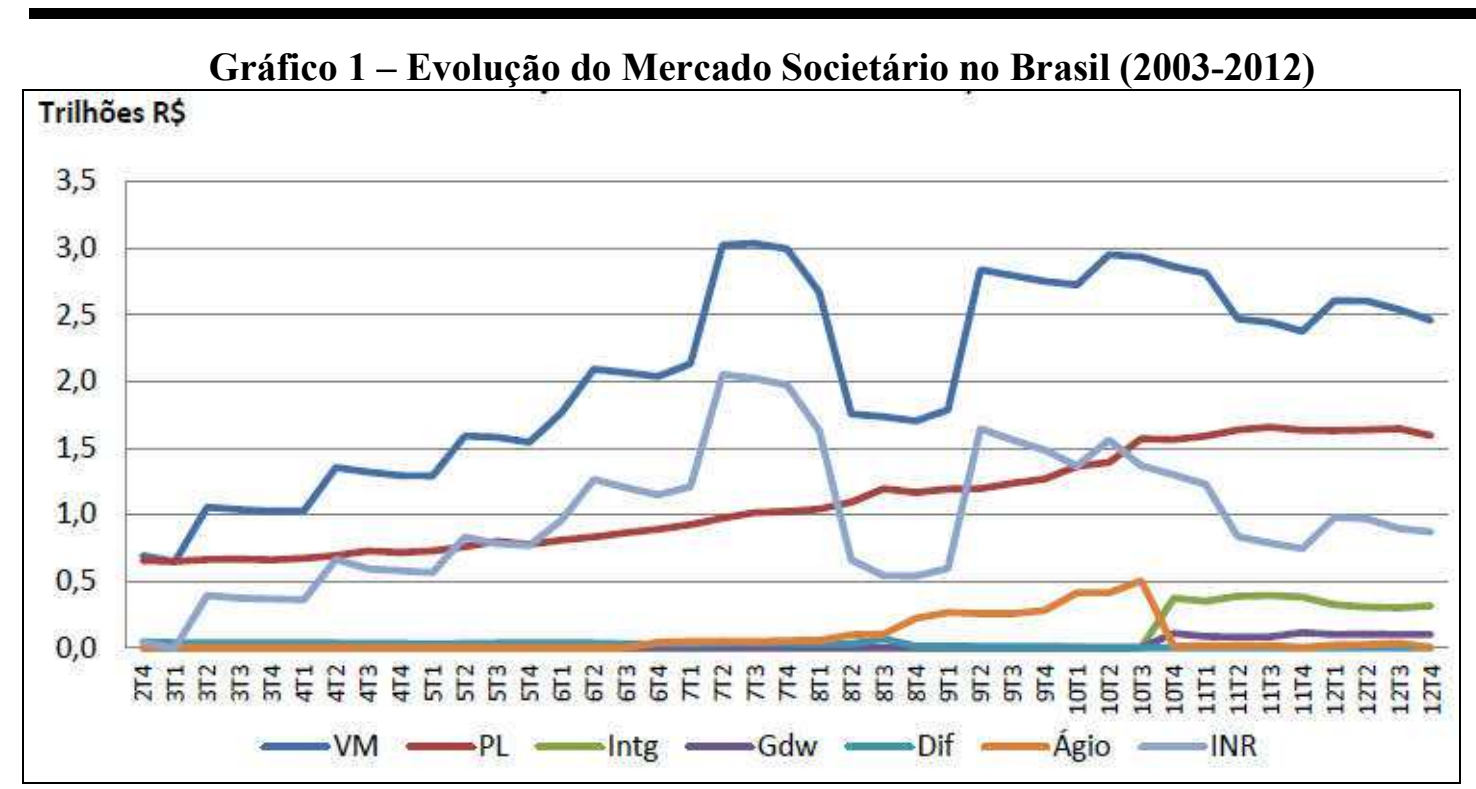

Legenda: 2T4 = Ano 2002; Trimestre 4

Fonte: Dados da pesquisa.

A análise gráfica inicial apresenta a limitação de que parte das variações é derivada do aumento ou diminuição da quantidade de empresas da amostra, que oscilou de 276 a 350 entidades, entre 2003 e 2012, conforme o Gráfico 2. Essa oscilação deve-se à entrada de novas empresas na Bolsa, enquanto outras saem, por extinção ou fusão.

Gráfico 2 - Empresas da Amostra (2003-2012)

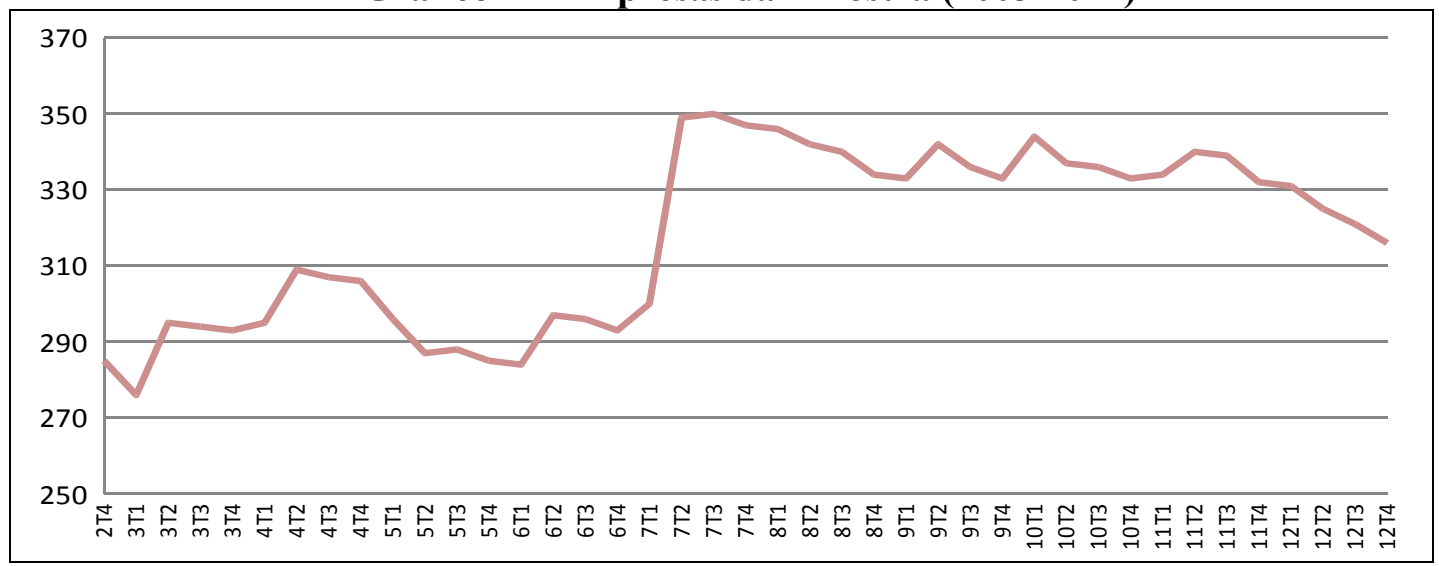

Legenda: 2T4 = Ano 2002; Trimestre 4

Fonte: Dados da pesquisa.

No intuito de reduzir a oscilação derivada da mudança da quantidade de empresas, os montantes de cada período foram divididos pela quantidade de entidades, resultando num valor médio para os valores das empresas. Da análise gráfica, percebeu-se que a linha apresenta correspondência com a linha dos valores agrupados do mercado.

A linha evidencia um crescimento no período, com uma depressão no ano de 2008, seguida de recuperação, corroborando a hipótese de pesquisa de que os intangíveis são 
corroídos em momentos de crise financeira. Nos anos seguintes, a linha apresenta uma relativa estabilidade com tendência de queda, conforme demonstra o Gráfico 3.

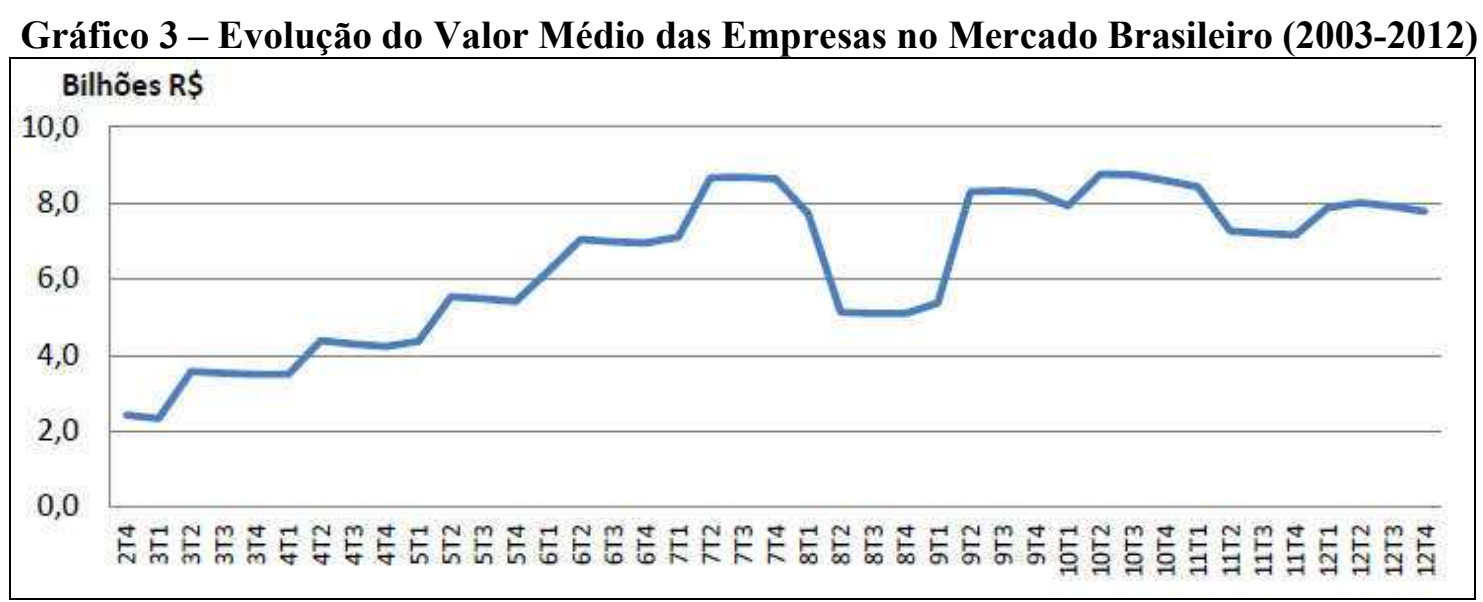

Legenda: 2T4 = Ano 2002; Trimestre 4

Fonte: Dados da pesquisa.

No intuito de minimizar aquelas distorções derivadas da entrada, saída ou omissão de dados, optou-se por trabalhar com os dados agrupados das empresas que tiveram informações da Bolsa de Valores divulgadas em cada período, entre 2003T1 e 2012T4 (40 períodos). Com base no valor total agrupado, foi extraída a média das valores das empresas, e comparada a variação entre um período e o seguinte, sendo que o período 1 indica o primeiro trimestre de 2003, e o período 40 indica o quarto trimestre de 2012.

As taxas de variação do valor de mercado no período oscilaram entre $-34 \%$ e $55 \%$, com tendência de decréscimo e menor dispersão, exceto pelo sobressalto durante a crise financeira de 2008, conforme demonstrado no Gráfico 4.

\section{Gráfico 4 - Taxa de Variação do Valor de Mercado Médio no Brasil (2003-2012)}

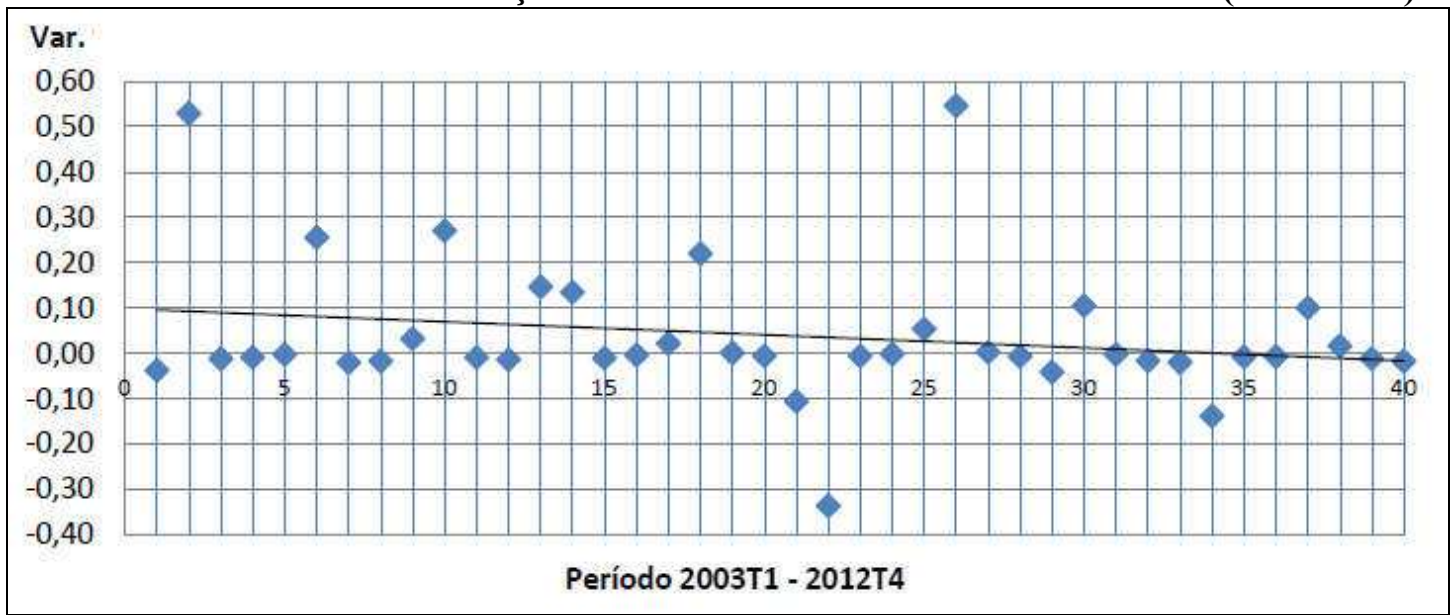

Legenda: 0 = Ano 2002 e Trimestre 4; 40 = Ano 2012 e Trimestre 4

Fonte: Dados da pesquisa.

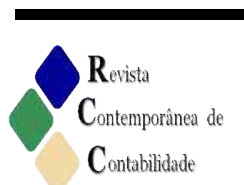

ISSN 2175-8069, UFSC, Florianópolis, v. 12, n. 27, p. 187-206, set./dez. 2015 
Considerando apenas a média da soma do valor de mercado das 147 empresas que tiveram valores negociados para todo o período, o valor de mercado das empresas teve o comportamento expresso em taxas de crescimento acumuladas, conforme demonstradas no Gráfico 5 durante o período de 2003T2 até 2012T4.

\section{Gráfico 5 - Acumulado da Taxa de Variação da Média do Valor de Mercado}

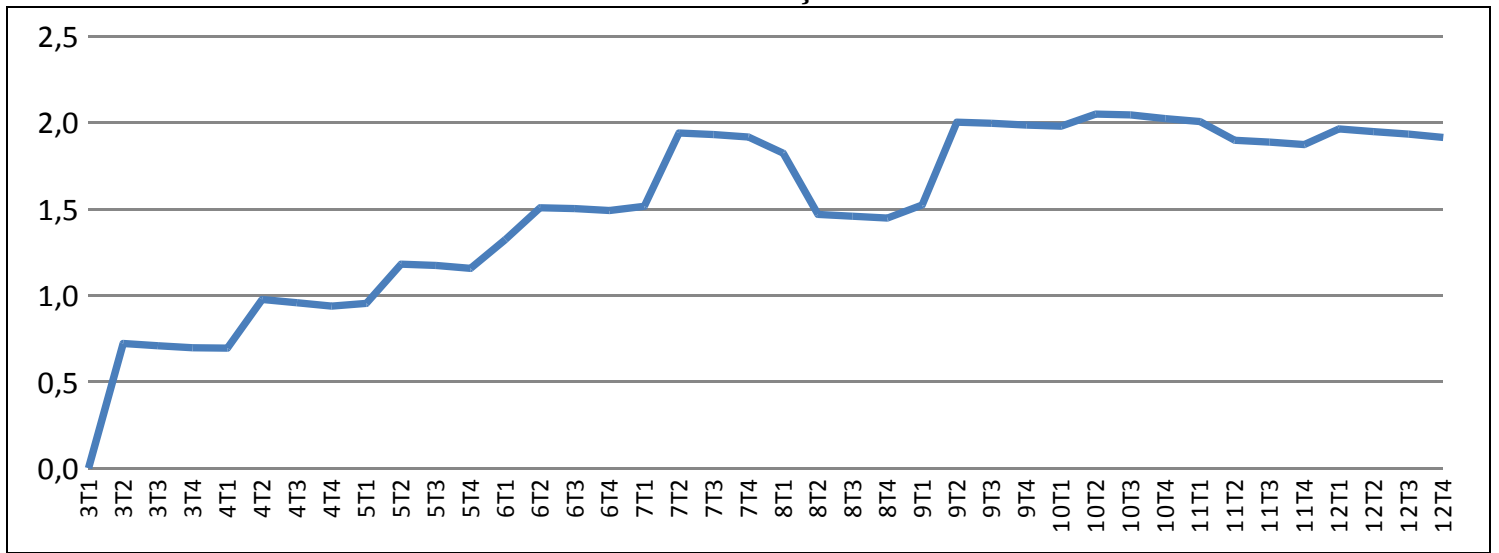

Legenda: 2T4 = Ano 2002; Trimestre 4

Fonte: Dados da pesquisa.

Conforme demonstrado no Gráfico 5, o crescimento médio do valor de mercado acumulado das empresas foi de aproximadamente $200 \%$ no período de 2003 a 2012 . Em relação ao período da crise de 2008, percebe-se, entre o início de 2007 e o final de 2008, uma queda de aproximadamente $25 \%$ do crescimento acumulado nos anos anteriores.

Ressalta-se que, antes da grande elevação nos primeiros trimestres de 2003, se deve, em parte, à recuperação da queda no valor de mercado, ocorrida no final de 2002, pela incerteza do mercado em relação à sucessão presidencial. De Medeiros e Daher (2008) revelaram que, naquele momento, o Ibovespa esteve no seu menor índice desde fevereiro de 1999.

As taxas de crescimento individualizadas variaram no tempo, alternando taxas de crescimento negativas e positivas. O Gráfico 6 apresenta as taxas de crescimento do valor de mercado, pelas suas médias e medianas.

O Gráfico 6 evidenciou as taxas de variação média e mediana do valor de mercado das 147 empresas que tiveram seus valores negociados durante todo o período da amostra. $\mathrm{O}$ valor médio decorre da soma de todos os valores, divididos pela quantidade de observações, enquanto o valor mediano refere-se à posição central dos valores entre os extremos.

$\mathrm{O}$ valor médio apresenta maior oscilação que o valor mediano, pois este sofre menos influência dos valores extremos. Conforme esperado, sem a influência dos valores extremos, a linha do valor mediano apresentou menor inclinação, mas ambas decrescentes de 2003 a 2012. 
Gráfico 6 - Comparativo da Taxa Média e Mediana de Variação do Valor de Mercado (2003-2012)

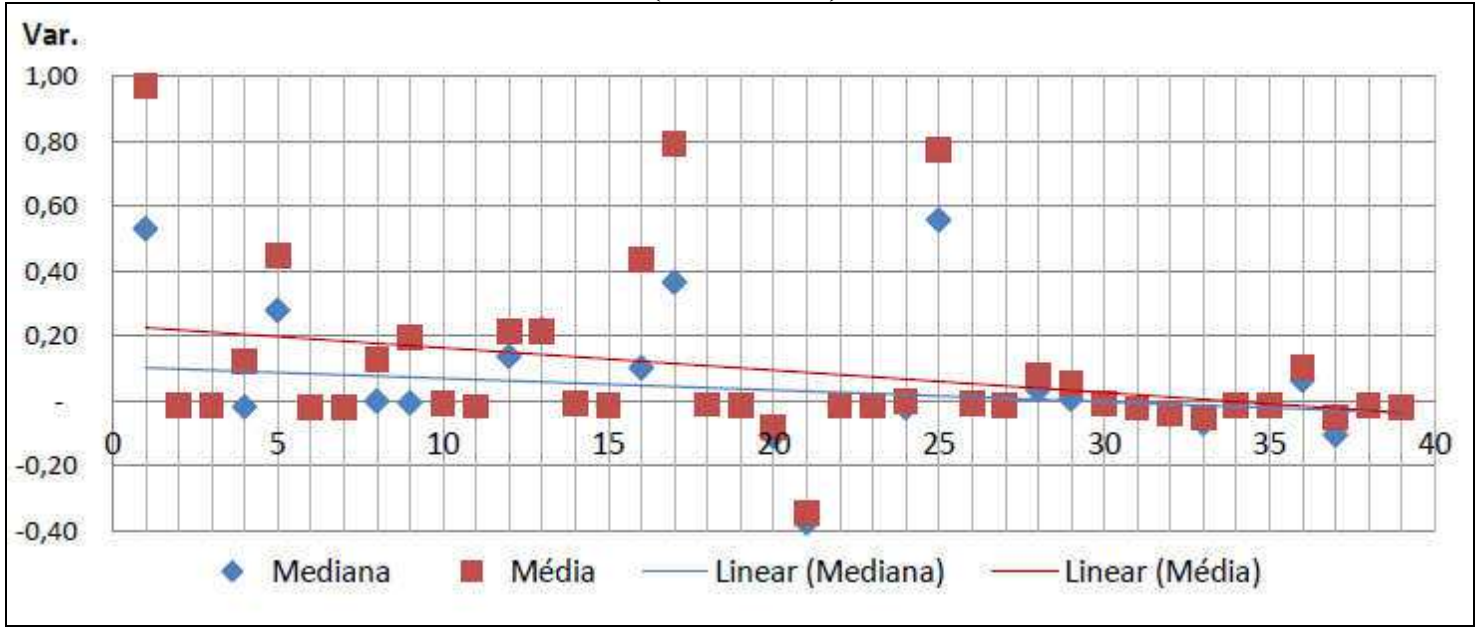

Legenda: $0=$ Ano 2002 e Trimestre 4; $40=$ Ano 2012 e Trimestre 4

Fonte: Dados da pesquisa.

Para identificar a real perda do mercado de capitais (BOVESPA), foi preciso recompor o quantitativo total de empresas listadas para cada período (entre 276 e 350), sendo que ainda foi mantida a correção dos valores pelo IPCA. Conforme demonstrado no gráfico geral das variáveis, o valor de mercado e o intangível não reconhecido têm relação muito próxima, cuja diferença advém do patrimônio líquido, que é novamente destacado no Gráfico 7.

\section{Gráfico 7 - Evolução do Valor de Mercado, Patrimônio Líquido e Intangível não Reconhecido no Brasil (2003-2012)}

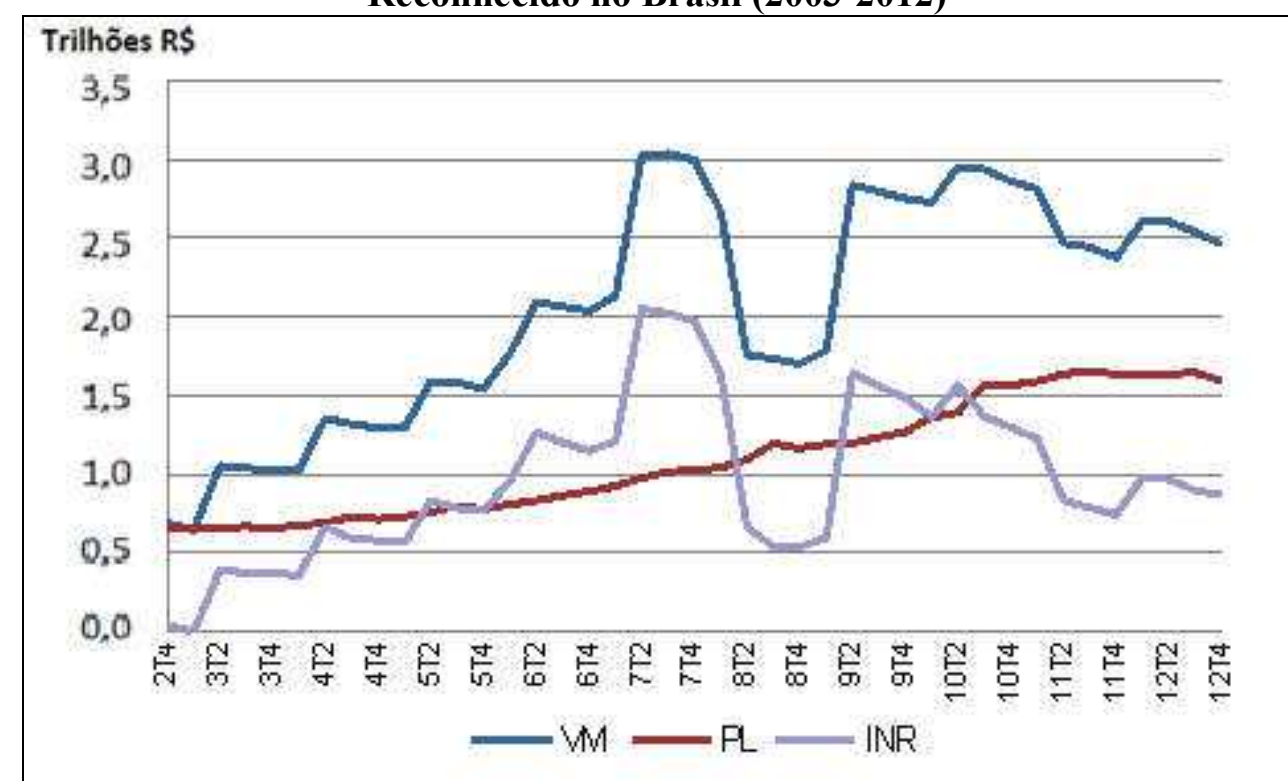

Legenda: 2T4 = Ano 2002; Trimestre 4

Fonte: Dados da pesquisa. 
A evolução apresentada no Gráfico 7 demonstra um aumento superior a R 2 trilhões no valor de mercado da amostra brasileira, entre 2003 e 2007. Por ocasião da crise financeira, em 2008, o mercado societário teve uma perda superior a R \$ 1,2 trilhão, parcialmente recomposta nos dois primeiros trimestres de 2009. Posteriormente, o valor de mercado das empresas brasileiras se manteve relativamente estável com tendência de baixa.

A acelerada evolução do valor de mercado (preço das ações), sem o correspondente aumento nas estimativas do valor real, denota características de bolha especulativa. Essa possibilidade foi identificada e não rejeitada para o mercado brasileiro entre 1999 e 2006 (DE MEDEIROS; DAHER, 2008).

Apesar da oscilação no valor de mercado acumulado das empresas negociadas na Bolsa de Valores de São Paulo, o patrimônio líquido dessas empresas manteve-se em contínuo e suave crescimento, totalizando 144\% de 2003 a 2012, o que, nesses termos, corrobora os resultados de Choi, Kwon, Lobo (2000), que identificaram que o mercado percebe positivamente os ativos intangíveis. Da comparação entre as linhas de valor de mercado e de patrimônio líquido, cuja diferença demonstra os intangíveis não reconhecidos, percebe-se pequena diferença em 2003 (R \$ 39 bilhões), seguido por um rápido crescimento até o ano de 2007, quando superou R $\$ 2$ trilhões. Uma variação de 5175\%.

Após a crise, esse intangível não reconhecido do mercado brasileiro foi reduzido a $\mathrm{R} \$$ 537 bilhões, queda de R\$1,49 trilhão, no encerramento do exercício de 2008. Foi uma queda de $73 \%$ do capital injetado pelos investidores, que não estavam lastreados em ativos líquidos.

Ainda em 2009, os intangíveis não reconhecidos recuperaram parte das perdas referentes à crise do subprime, alcançando R\$ 1,6 trilhão no segundo trimestre de 2009, que posteriormente foi sendo reduzido, alcançando R\$ 867 bilhões no encerramento de 2012. Nessa época, o intangível não reconhecido representou apenas $42 \%$ do montante do segundo trimestre de 2007, quando chegou ao seu maior valor.

Identificou-se que o intangível não reconhecido, resultado da diferença entre o valor de mercado e o patrimônio líquido, cresceu R\$ 828 bilhões no período de 10 anos, corroborando parcialmente a pesquisa de Serra e Saito (2015), que em média o valor de mercado das empresas brasileiras é de 2,12 vezes o capital investido, tendo oscilado entre 1,45 e 4,50, no período de 2005 a 2014, bem como corrobora os achados por Machado e Famá (2011) que evidenciaram o crescimento da intangibilidade entre 2000 e 2006. A crise financeira consumiu R\$ 1,3 e R\$ 1,5 trilhão em valor de mercado e intangíveis não reconhecidos, respectivamente, acompanhando a trajetória do valor de mercado, na suposta 'bolha especulativa' e na crise do subprime. Em termos relativos, o valor de mercado e o intangível não reconhecido foram consumidos em $44 \%$ e $73 \%$, respectivamente, evidenciando a maior sensibilidade do intangível ao cenário econômico.

Esses dados corroboram a pesquisa de Salamudin et al. (2010) que evidenciou o aumento da intangibilidade das empresas entre 2000 e 2006. Na outra lacuna, após crise financeira e incorporação dos padrões internacionais de contabilização, ao considerar a diferença entre o valor de mercado e o dito intangível não reconhecido, essa redução corrobora os achados de Castro e Benetti (2013) que sugeriram que quanto maior o registro de ativos intangíveis, menor será a diferença entre o valor contábil e o valor de mercado.

Seguindo a metodologia de agregar todas as empresas com dados disponíveis no período, analisaram-se os demais intangíveis ou em potencial, como o intangível puro, o goodwill, o ágio intangível e o diferido, conforme Gráfico 8. 
Gráfico 8 - Evolução dos Intangíveis no Mercado Societário Brasileiro (2003-2012)

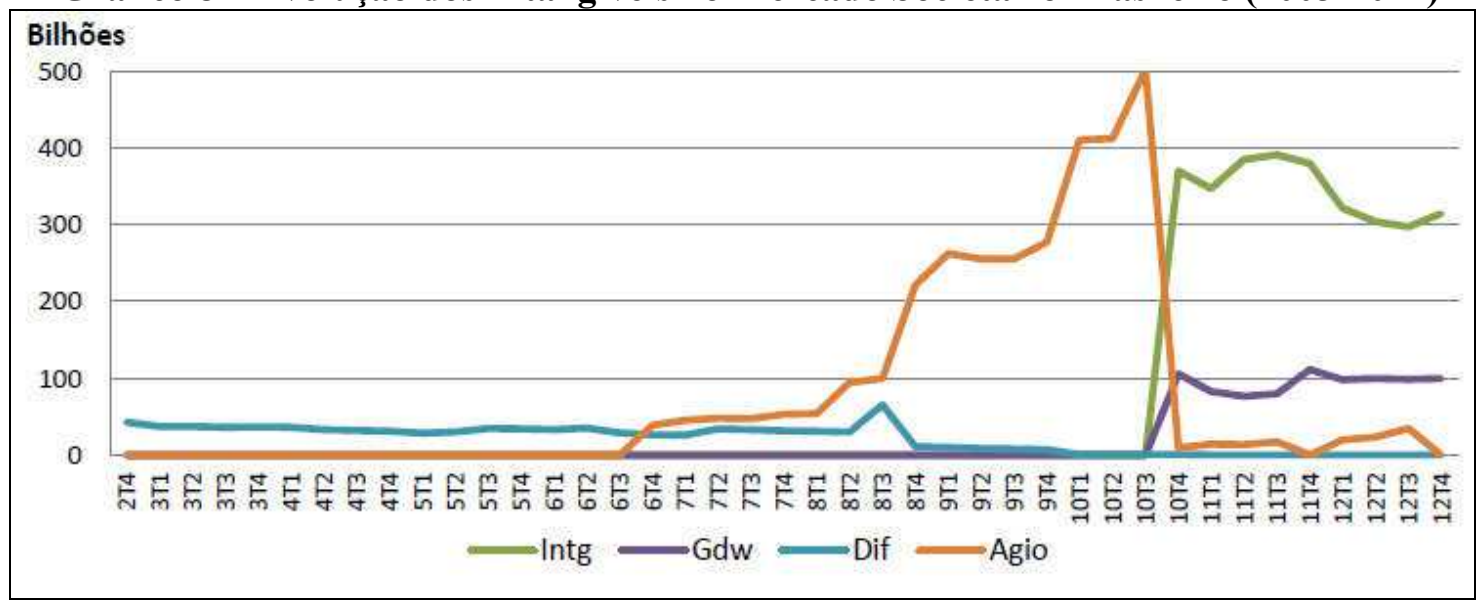

Legenda: 2T4 = Ano 2002; Trimestre 4

Fonte: Dados da pesquisa.

Em relação às variáveis analisadas, percebe-se que não ocorreram grandes oscilações até 2008, que poderiam ser derivadas da crise do subprime. No entanto, a partir do encerramento de 2008, o ágio e o diferido apresentaram uma grande variação, que culminou no encerramento de 2010.

O intangível decorrente de bens incorpóreos reconhecidos e o goodwill começaram a ser evidenciados nas demonstrações contábeis a partir do encerramento de 2010, quando alcançaram juntos R $\$ 475$ bilhões. Em relação ao último trimestre de 2012, esses intangíveis apresentaram uma queda de 13\%, que corresponde a R\$ 61 bilhões. De acordo com as pesquisas de Rodrigues, Elias e Campos (2014), as informações sobre Pesquisa \& Desenvolvimento passaram a mostrar-se relevantes com base na mudança na legislação.

As alterações na legislação societária foram determinantes para as variações, como a Lei n. 11.638/2007, a Medida Provisória n. 449/2008 e a Lei n. 11.941/2009. As alterações na Lei n. 6.404/1976, impostas pela Lei n. 11.638/2007, criaram uma nova estrutura para o Balanço Patrimonial, provocando alterações na estrutura então vigente. No grupo intangível, deveriam ser classificados os direitos que tivessem por objeto bens incorpóreos destinados à manutenção da companhia ou exercidos com essa finalidade, incluído o fundo de comércio adquirido. Antes disso, a Deliberação CVM n. 488/2005 já havia inserido esse destaque para os intangíveis.

Com base na evidenciação do reconhecimento da expectativa de rentabilidade futura como goodwill, no grupo de intangíveis, o ágio reconhecido anteriormente em conta específica teve uma redução drástica de $98 \%$. A conta de registro do ágio apresentou valores superiores durante os três primeiros trimestres do ano, e uma queda drástica no encerramento do exercício. No último trimestre de 2012, o valor correspondeu a $0,00026 \%$ do valor do terceiro trimestre de 2010.

Os valores reconhecidos como ativos diferidos tiveram seu ápice no terceiro trimestre de 2008, com aproximadamente R $\$ 6,7$ bilhões, seguidos de uma queda de $83 \%$. No encerramento do exercício de 2012, ainda restavam reconhecidos R 115 milhões.

Em relação ao ativo diferido, a Lei n. 11.638/2007 restringiu as despesas pré- 
operacionais e os gastos de reestruturação que teriam efetiva contribuição para o aumento do resultado de mais de um período. Os demais itens, antes classificados no diferido, deveriam ser reclassificados para outros grupos, como o fundo de comércio ao intangível, respeitando os requisitos de reconhecimento.

Posteriormente, a Lei n. 11.941/2009 extinguiu esse grupo de ativos, sendo que o saldo existente, no encerramento de 2008 , de acordo com a sua natureza, deveria ser realocado aos demais grupos e, na impossibilidade de reclassificação, poderia permanecer até a completa amortização. Em termos absolutos, os intangíveis reconhecidos cresceram de R\$ 43 para R \$ 414 bilhões, entre 2003 e 2012. Uma variação de 860\%.

Embora Souza e Prado (2014) tenham identificado que a transição de normas com adoção dos International Financial Reporting Standards (IFRS), não causou diferenças estatisticamente significativas nas métricas de valor, as contas contábeis foram de fato alteradas pela legislação citada, sendo relevante sua influência na movimentação daqueles valores.

\section{Considerações Finais}

A presente pesquisa teve como principal objetivo analisar e identificar o que ocorreu com os intangíveis e o valor de mercado na crise de 2008. Nesse contexto, foi identificado que, de 2003 a 2012, o valor de mercado e os intangíveis tiveram um significativo crescimento, sendo que, durante a crise financeira, foram bastante reduzidos, com destaque para os intangíveis não reconhecidos, conforme evidenciados nos resultados descritivos.

A análise permitiu identificar a evolução do valor de mercado das empresas listadas na BOVESPA que resultou num aumento superior a R\$ 2 trilhões, entre 2003 e 2007. Esses achados corroboram, no Brasil, os resultados obtidos por Salamudin et al. (2010) em outros mercados emergentes. Por ocasião da crise financeira, em 2008, foram consumidos R $\$ 1,3$ e $\mathrm{R} \$ 1,5$ trilhão em valor de mercado e intangíveis não reconhecidos, respectivamente, corroborando a hipótese de pesquisa, pois, após a crise, o intangível não reconhecido foi reduzido em $74 \%$ do capital injetado pelos investidores, que não estavam lastreados em ativos líquidos. Nesse momento, o intangível não reconhecido representou apenas $42 \%$ do montante registrado no segundo trimestre de 2007, quando chegou ao seu maior valor.

Ainda em 2009, os intangíveis não reconhecidos recuperaram parte das perdas referente à crise do subprime alcançando R\$ 1,6 trilhão, no segundo trimestre de 2009, que posteriormente foi reduzido alcançando $\mathrm{R} \$ 867$ bilhões no encerramento de 2012 enquanto o valor de mercado das empresas brasileiras se manteve relativamente estável com tendência de baixa. Nesse período, o patrimônio líquido dessas empresas manteve-se em contínuo e suave crescimento, de 144\%, confirmando as expectativas estabelecidas por Lev (2001) que evidenciou, em mercados desenvolvidos, o crescimento de tal indicador.

Assim, entende-se que o objetivo da pesquisa foi alcançado ao contribuir com a identificação da evolução dos intangíveis e do valor de mercado das empresas brasileiras durante a crise financeira de 2008. As evidências empíricas dos efeitos da crise no mercado de capitais e da evolução do valor de mercado e dos intangíveis podem ser úteis como direcionadores para decisão dos gestores e profissionais contábeis.

A magnitude do custo da crise financeira ( $\mathrm{R} \$ 1,5$ trilhão) mensurado na pesquisa, que foi causado aos investidores, pode ser utilizada como indicadora da necessidade de pesquisas 
que tentem prever e minimizar tais crises. Aliás, essa perspectiva de dano causado ao mercado que, sob a ótica de pesquisas citadas, poderia ser decorrente de uma 'bolha especulativa' anterior, seria uma das recomendações para perspectivas futuras, bem como uma análise dos intangíveis reconhecidos a partir de 2008 por um período mais extenso, prejudicada na análise devido ao reduzido período após implantação dos novos padrões contábeis.

\section{Referências}

ANTUNES, M. T.; MARTINS, E. Capital Intelectual: verdades e mitos. Revista Contabilidade e Finanças, São Paulo, n. 29, p. 41-54, maio/ago., 2002.

BALLOW, J.; BURGMAN, R.; MOLNAR, J. Managing for shareholder value: intangibles, future value and investment decision. Journal of Business Strategy, [s. 1.], v. 25, n. 3, p. 26$34,2001$.

BARTH, M. E.; BEAVER, W. H.; LANDSMAN, W. R. The Relevance of the Value Relevance Literature for Financial Accounting Standard Setting: another view. Journal of Accounting and Economics, [s. 1.], v. 31, n. 1, p. 77-104, 2001.

BARTH, M. E. et al. Brand values and capital market valuation. Review of Accounting Studies, Berkeley, v. 3, p. 41-68, 1998.

BARTH, M. E.; KASZNIK, R.; MCNICHOLS, M. F. Analyst Coverage and Intangible Assets, 2000. Disponível em: <http://ssrn.com/abstract=263981>. Acesso em: 18 out. 2013.

BEAVER, W. H.; RYAN S. G. Accounting Fundamentals of the Book-to-Market Ratio.Financial Analysts Journal, New York, v. 49, n. 6, Nov./Dec. 1993.

BELEM, V. C.; MARQUES, M. M. A influência dos ativos intangíveis na rentabilidade do patrimônio líquido das empresas brasileiras. In: CONGRESSO USP DE CONTROLADORIA E CONTABILIDADE, 12., 2012, São Paulo. Anais... São Paulo: USP, 2012.

BOULTON, R. S.; LIBERT, B. D.; SAMEK, S. M. Cracking the value code. New York: Harper Collings Publishers, 2001.

CASTRO, W. B. L.; BENETTI, C. The Impact of Intangible Assets in the Market Value of Companies That Compose the Index of Brazilian Stock Exchange. In: ANNUAL LONDON BUSINESS RESEARCH CONFERENCE, 8., 2013, London. Anais... London: Imperial College, 2013.

CHAN, L. K. C.; LAKONISHOK, J.; SOUGIANNIS, T. The stock market valuation of research and development expenditures. The Journal of Finance, [s. 1.], v. 56, n. 6, p. 24312456, 2001. 
CHOI, W. W.; KWON, S. S.; LOBO, G. J. Market Valuation of Intangible Assets.Journal Business Research, [s. 1.], n. 49, p. 35-45, 2000.

DE MEDEIROS, O. R.; DAHER, C. E. Evidências de Bolhas Especulativas no Mercado de Ações Brasileiro. In: ENCONTRO DA ASSOCIAÇÃO NACIONAL DE PÓSGRADUAÇÃO E PESQUISA EM ADMINISTRAÇÃO (EnANPAD), 32., 2008.Anais... Rio de Janeiro: Anpad, 2008.

EDVINSON, L.; MALONE, M. S. Intellectual Capital: Realizing your Company's True Value by Finding its Hidden Brainpower. New York: Harper Business, 1997.

FAMA, E. F. Efficient capital markets II. The Journal of Finance, [s. 1.], v. 46, n. 5, p. 1575$1617,1991$.

FAMA, E. F. Efficient capital markets: a review of theory and empirical work. Journal of Finance, [s. 1.], v. 25, n. 2, p. 383-417, 1970.

FERNANDES, B. V. R. Evidências de Bolhas de Preços no Mercado Acionário Brasileiro. 2008. 99 f. Dissertação (Mestrado em Ciências Contábeis) - Programa Multi-Institucional e Inter-Regional de Pós-Graduação em Ciências Contábeis, Universidade de Brasília, Universidade Federal da Paraíba, Universidade Federal do Rio Grande do Norte, Brasília, 2008.

FLOWER, J. Global Financial Reporting. New York: Palgrave, 2002.

FREZATTI, F.; AGUIAR, A. B.; GUERREIRO, R. Diferenciações entre a Contabilidade Financeira e Gerencial: uma pesquisa empírica a partir de pesquisadores de vários países. Revista Contabilidade e Finanças, São Paulo, n. 44, p. 9-22, maio/ago., 2007.

GHOSH, D.; WU, A. Intellectual capital and capital markets: additional evidence. Journal of Intellectual Capital, [s. 1.], v. 8, n. 2, p. 216-235, 2007.

HENDRIKSEN, E. S.; VAN BREDA, M. F. Teoria da Contabilidade. 5. ed. São Paulo: Atlas, 2011.

HITCHNER, J. R. Financial valuation: applications and models. 2. ed. Hoboken: Wiley, 2006.

IUDICIBUS, S. Teoria da Contabilidade. 10. ed. São Paulo: Atlas, 2010.

KANE, E. J.; UNAL, H. Modeling structural and temporal variation in the market's valuation of banking firms. The Journal of Finance, [s. 1.], v. 14, n. 1, 1990.

KERR G.; DARROCH J. Performance in the contemporary conglomerate. Academy of Strategic Management Journal. [s. 1.], v. 3, p. 21-32, Jan. 2004. 
LEV, B. Intangibles: management, measurement, and reporting. Washington, D.C., Brookings Institution Press, 2001.

LEV, B. Remarks on the Measurement, Valuation, and Reporting of Intangible Assets.

FRBNY Economic Policy Review, New York, v. 9, n. 3, p. 17-22, Sept. 2003.

LEV, B. Sharpening the intangibles edge. Harvard Business Review, Cambridge, v. 82, n. 6, p. 109-16, 2004.

LEV, B. Intangible Assets: concepts and measurements. Encyclopedia of Social Measurement, New York, v. 2, p. 299-305, 2005.

MACHADO, J. H.; FAMÁ, R. Ativos Intangíveis e Governança Corporativa no Mercado de Capitais Brasileiro. Revista Contemporânea de Contabilidade, Florianópolis, v. 8, n. 16, p. 89-110, jul./dez., 2011.

MARTINS, E. Contribuição à avaliação do ativo intangível. 1972. 107 f. Tese (Doutorado em Contabilidade) - Faculdade de Economia, Administração e Contabilidade, Universidade de São Paulo, São Paulo, 1972.

MARTINS, G. A.; THEÓPHILO, C. R. Metodologia da Investigação Científica para Ciências Sociais Aplicadas. 2. ed. São Paulo: Atlas, 2009.

PEREZ, M. M.; FAMÁ, R. Ativos Intangíveis e o Desempenho Empresarial. Revista Contabilidade e Finanças, São Paulo, n. 40, p. 7-24, 2006.

ROBERTS, P. W.; DOWLING, G. R. Corporate Reputation and Sustained Superior Financial Performance.Strategic Management Journal, [s. 1.], n. 23, p. 1077-1093, 2002.

RODRIGUES, J. M.; ELIAS, W. G.; CAMPOS, E. S. Relevância da Informação Contábil: uma análise dos efeitos da contabilização dos gastos com pesquisa e desenvolvimento com a aplicação da Lei 11.638/07 no mercado brasileiro. In: CONGRESSO USP DE

CONTROLADORIA E CONTABILIDADE, 14., 2014, São Paulo. Anais... São Paulo: USP, 2014.

ROSS, G.; ROSS, J. Measuring your company's intellectual performance. Long Range Planning, [s. 1.], v. 30, n. 3, 1997.

SALAMUDIN, N. et al. Intangible assets valuation in the Malaysian capital market. Journal of Intellectual Capital, Reino Unido, v. 11, n. 3, p. 391-405, 2010.

SANTOS, J. L. et al. Teoria da Contabilidade: introdutória, intermediária e avançada. São Paulo: Atlas, 2007.

SCOTT, W. R. Financial accounting theory. Toronto: Prentice Hall, 2007. 
SERRA, R. G.; SAITO, A. T. Determinantes do Price to Book, Setor Regulado e Estratégias de Investimento. In: CONGRESSO USP DE CONTROLADORIA E CONTABILIDADE, 15., 2015, São Paulo. Anais... São Paulo: USP, 2015.

SOUZA, K. G.; PRADO, T. A. R. Impactos da Adoção Completa das IFRS nas Métricas de Valor das Companhias Abertas Brasileiras. In: CONGRESSO USP DE CONTROLADORIA E CONTABILIDADE, 14., 2014, São Paulo. Anais... São Paulo: USP, 2014.

SMITH, M. Research Methods in Accounting. London: SAGE, 2003.

WATTS, R. L.; ZIMMERMAN, J. L. Positive accounting theory. New Jersey: Prentice-Hall, 1986. 
